\title{
REGIONAL RECOVERY OF GRAVITY ANOMALY FROM THE INVERSION OF DIAGONAL COMPONENTS OF GOCE GRAVITATIONAL TENSOR: A CASE STUDY IN ETHIOPIA
}

\author{
Mehdi Eshagh ${ }^{2}$, Andenet A. Gedamu ${ }^{1,3}$, Tulu B. Bedada ${ }^{3}$ \\ ${ }^{1}$ Addis Ababa University, Addis Ababa Institute of Technology, School of Civil and \\ Environmental Engineering, Addis Ababa, Ethiopia. \\ ${ }^{2}$ Department of Engineering Science, University of West, Sweden. \\ ${ }^{3}$ Entoto Observatory and Research Centre, Ethiopian Space Science and Technology Institute, \\ Addis Ababa, Ethiopia.
}

\begin{abstract}
The tensor of gravitation is traceless as the gravitational field of the Earth is harmonic outside the Earth's surface. Therefore, summation of the $2^{\text {nd }}$-order horizontal derivatives on its diagonal components should be equal to the radial one but with the opposite sign. The gravity field can be recovered locally from either of them, or even their combination. Here, we use the in-orbit diagonal components of the gravitational tensor measured by the gravity field and steady state ocean circulation explorer (GOCE) mission for recovering gravity anomaly with a resolution of $1^{\circ} \times 1^{\circ}$ at sea level in Ethiopia. In order to solve the system of equations, derived after discretisation of integral equations, the Tikhonov regularisation is applied and the bias of this regularisation is estimated and removed from the estimated gravity anomalies. The errors of the anomalies are estimated and their significance of recovery from these diagonal components is investigated. Statistically, the difference between the recovered anomalies from each scenario is not significant comparing to their errors. However, their joint inversion of the diagonal components improved the solution by about $1 \mathrm{mGal}$. Furthermore, the inversion processes are better stabilised when using errors of the input data compared with its exclusion, but at the penalty of degradation in accuracy of the estimates.
\end{abstract}

Keywords: Gravitational field, Laplace condition, Regularisation, error estimation

\section{INTRODUCTION}

The European Gravity field and steady-state Ocean Circulation Explorer (GOCE) was the first satellite mission, which measured the gravitational tensor along the orbit of its satellite (ESA, 1999). Except the Polar Regions, the data of GOCE have very good coverage all over the Earth 
with uniform quality. The $2^{\text {nd }}$-order derivatives of geopotential, or gravity gradients, measured by GOCE are more sensitive to medium wavelength component of gravity field than previous gravity satellites, allowing us to determine gravity anomalies with better spatial resolution. The GOCE data can also be used for local gravitational field recovery directly with less-processed data. In this case, only those orbital passes over the study area are required rather than the data with a global coverage. Theoretically, the tensor of gravitation has a zero trace as the gravity field of the Earth is harmonic outside the Earth's surface. This property can be used to recover local gravity field from $2^{\text {nd }}$-order horizontal derivatives of geopotential on its diagonal components. Therefore, in two ways the gravity field can be recovered locally, one from the $2^{\text {nd }}$-order radial derivative and another from horizontal derivatives. The subject of this paper is dealing with comparison, errors estimation and significance analysis of gravity anomalies recovered from both radial and horizontal derivatives over Ethiopia.

There are different techniques used for recovering regional gravity field from $2^{\text {nd }}$-order derivatives of the gravity field locally see e.g. Eicker (2008). Least-squares collocation (Krarup 1969) is one of the famous approximating method see e.g. the works done by Arabelos and Tscherning (1990, 1993 and 1995), Tscherning (1988, 1989), Tscherning et al. (1990) and Yildiz (2012). Also, the gravity field can be recovered using a direct integral method, which in fact does two separate computations in one step, integrating the satellite over the mean orbital sphere and continuing them downward to sea level; see Tscherning et al. (1990), Eshagh (2011a), Eshagh (2012) and Sjöberg and Eshagh (2012). Another approach is to determine gravity field from the inversion of integral equations. Reed (1973) developed integral equations for second order partial derivatives of extended Stokes formula to recover the gravity anomaly. Xu (1992) discussed a similar issue using the Tikhonov regularisation. The truncated singular value decomposition was used by $\mathrm{Xu}$ (1998) for inversion of $2^{\text {nd }}$-order radial derivatives of geopotential to gravity anomalies while Kotsakis (2007) used the same method with a covariance-adaptive method for regularisation. Toth et al. (2004) presented the idea of upward/downward continuation of the satellite gradiometry data to the mean orbital sphere. Xu (2009) introduced an iterative generalised cross-validation method for simultaneous estimation of the regularisation and variance components (VCs) with an example of recovering the gravity anomaly from the $2^{\text {nd }}$-order derivatives of geopotential. Janak et al. (2009) investigated the inversion of full gravitational tensor described in a geocentric frame to recover the gravity anomalies at sea level. Eshagh (2011b) studied the inversion of stochastically-modified integral for gravity anomaly recovery from the derivatives and Eshagh (2011c) investigated the effect of the spatial truncation error (STE) of integral formula on recovery of gravity anomaly. Eshagh and Sjöberg (2011) performed a similar study for inversion and combination of the full tensor of gravitation using the variance component estimation process for optimal weighting. Eicker et al. (2013) used radial basis functions for regional gravitational field modelling, which allows for regional tailoring of the regularization. Eshagh and Ghorbannia (2014) presented a strategy for local determination of gravity anomalies from orbital and gradiometric data considering the effect of spatial truncation error on the estimated variance components. Šprlak et al. (2014) and Šprlak and Novák (2014) have investigated the issue of downward continuation of the satellite gradiometric data. Janak et al. (2014) recovered the quasigeoid from GOCE meanwhile combining them with terrestrial data in Auvergne. Sebera et al. (2015) studied the problem of downward continuations using Abel-Poisson's integral inversion. Pitoňák et al. (2016a) performed the inversion of $2^{\text {nd }}$-order derivatives data to gravity disturbances at sea level over central Europe. Later, Pitoňák et al. (2017) applied the same methodology for recovering gravity 
disturbances from the real GOCE data and they investigated the possibility of inverting the $3^{\text {rd }}$ order derivatives of the gravity field to gravity anomalies over the same area. Finally, Naeimi and Bouman (2017) studied the contribution of the GOCE gravity gradients to regional gravitational field solutions by employing radial basis functions.

So far the GOCE data has been used for local gravity field recovery over different areas, but no investigation was performed over Ethiopia. In most of the studies, some components of the gravitational tensor have been used for local gravity field recovery, but Eshagh (2011a) mentioned that only the diagonal components of this tensor are suitable for such a purpose. No attempt was made to see in what way, these diagonal components can be used and how much improvements can be achieve by combining them. Furthermore, error estimations of the recovered anomalies and the significance of the differences between the recovered anomalies from $2^{\text {nd }}$-order radial and horizontal derivatives are investigated as well.

\section{THEORY}

The gravitational tensor is trace-free meaning that the sum of the diagonal components of this tensor is zero as the Earth's gravity field is harmonic outside the Earth's surface. The local-north oriented frame is used to define the partial derivatives of the Earth's gravity field. This frame has its origin at the satellite centre, its $z$-axis is along the geocentric distance of satellite in upward direction, $x$-axis is pointing to the north and the frame is left handed. In matrix theory, the trace operator is invariant, which means that the trace of the gravitational tensor does not depend on the type of frame. In fact, this tensor is trace-less even in gradiometer reference frame. Here, we use the local north-oriented frame for defining the mathematical models, as the directions of $x$ and $y$ - axis of the frame are independent of the satellite orbit. In such a frame, it is straightforward to write the following equation for a trace-free tensor:

$$
T_{z z}=-\left(T_{x x}+T_{y y}\right)
$$

where $T_{z z}, T_{x x}$ and $T_{y y}$ are the $2^{\text {nd }}$-order partial derivatives of the disturbing potential $T$, along $z, x$ and $y$-axis, respectively.

Eq. (1) shows that the summation of the derivatives along $x$ - and $y$-axis is the same as the one along $z$-axis but with opposite sign. This means that the same mathematical model, which is used for inverting $T_{z z}$, can be used for inversion of this summation term in the right hand side of Eq. (1). However, one issue is the quality of the recovered gravity anomalies and the noise level of the data. It is expected to see larger error in gravity anomalies obtained from this summation than that of $T_{z z}$.

The gravity anomaly at sea level can be computed from $T_{z z}$ by using the $2^{\text {nd }}$-order radial derivative of the extended Stokes formula (Reed 1973):

$$
T_{z z}=\frac{R}{4 \pi} \iint_{\sigma_{0}} S_{z z}(r, \psi) \Delta g \mathrm{~d} \sigma
$$

where $R$ is the mean radius of the Earth, $T_{z z}$ is the gravity gradient, measured at satellite level. $\Delta \mathrm{g}$ is the gravity anomaly at sea level, $\psi$ is the geocentric angle between the computation and integration points, $\sigma_{0}$ the integration area, and 
$S_{z z}(r, \psi)=\frac{t^{3}}{R^{2}}\left\{1-t \cos \psi\left[\frac{3\left(1-t^{2}\right)}{D^{5}}-\frac{4}{D^{3}}\right]-\frac{1+t^{2}}{D^{3}}-\frac{10}{D}-18 D+2-3 t \cos \psi\left[15-6 \ln \left(\frac{1-t \cos \psi+D}{2}\right)\right]\right\}$

With $t=R / r, \quad D=\sqrt{1-2 t \cos \psi+t^{2}}$, and $r$ is the geocentric distance of satellite.

The kernel $S_{z z}(r, \psi)$ is isotropic, which means that it is not a function of azimuth. This kernel is well-behaved function (Eshagh 2011a) with high value at the computation point and decays uniformly down to zero. Eshagh (2011a) mentioned such kernels are suitable for local integral inversion as the STE will be reducible when the inversion is performed over the study area and the results in the central part are selected. In other words, those recovered anomalies defected by the STE placed close to the marginal areas are trimmed off. Figure 1 represents the plot of this kernel and shows that the contribution of far-zone data for $\psi>10^{\circ}$, are considerably smaller than those in the near-zone area.

According to Eqs. (1) and (2), it will not be difficult to conclude that:

$$
-T_{x x}-T_{y y}=\frac{R}{4 \pi} \iint_{\sigma_{0}} S_{z z}(r, \psi) \Delta g \mathrm{~d} \sigma
$$

As we can see from Eq. (4), the same integral formula can be constructed for inverting $-\left(T_{x x}+T_{y y}\right)$ to gravity anomaly at sea level.

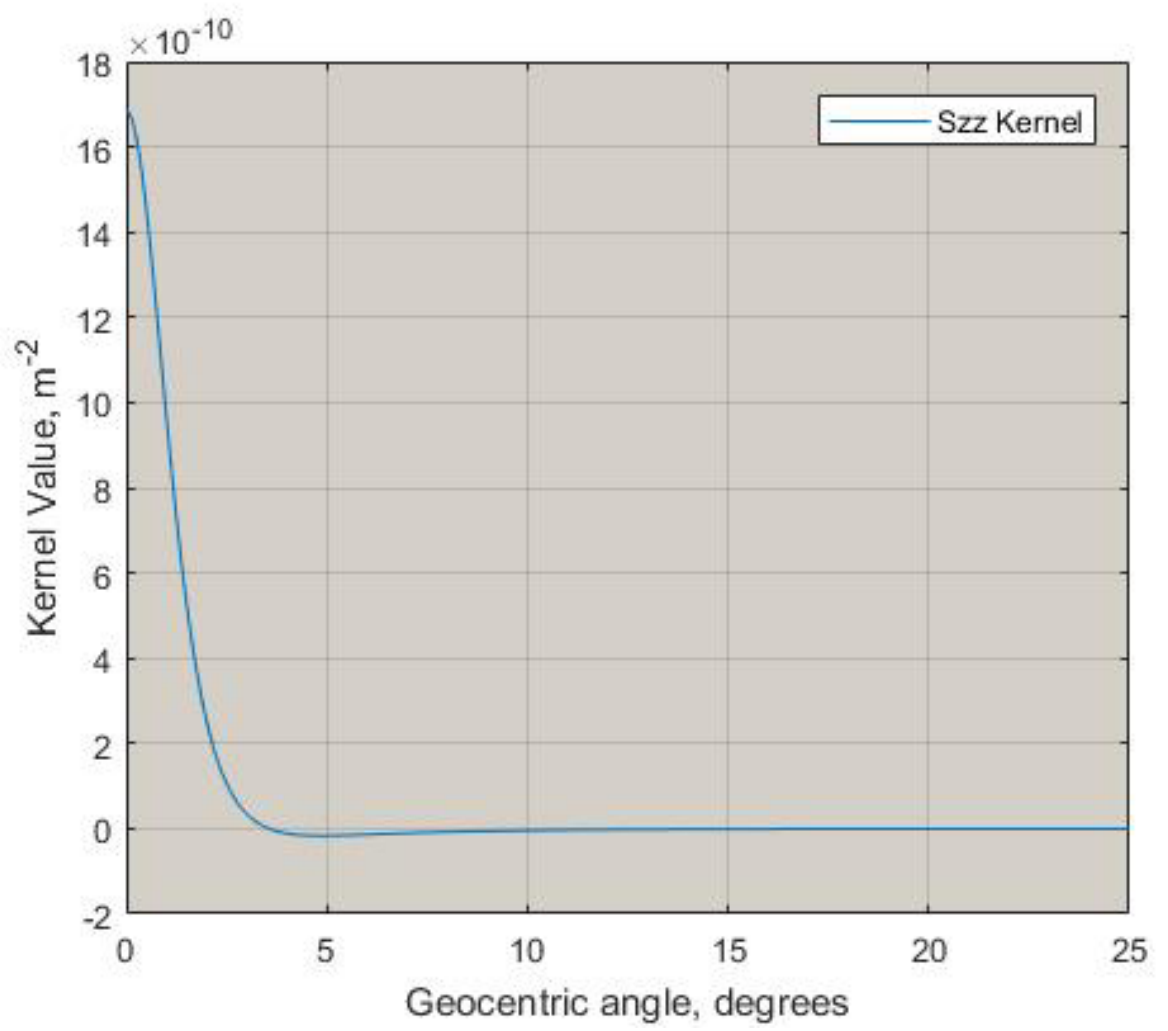

Fig 1. Behaviour of $\mathrm{S}_{\mathrm{zz}}(r, \psi)$ 


\section{SOLUTION OF INTEGRAL EQUATIONS}

Eq. (2) is of the Fredholm integral equation of the first kind. In order to solve this equation numerically, the integral should be discretised according to the desired spatial resolution of gravity anomalies. The discretised form of integral can be written in a matrix form of system of equations, or Gauss-Markov model:

$$
\mathbf{A x}=\mathbf{L}-\boldsymbol{\varepsilon}, \mathrm{E}\{\boldsymbol{\varepsilon}\}=0 \text { and } \mathrm{E}\left\{\boldsymbol{\varepsilon}^{\mathrm{T}}\right\}=\sigma_{0}^{2} \mathbf{Q}
$$

where $\mathbf{A}$ is the coefficient matrix, $\mathbf{x}$ is the vector of unknown parameters being estimated in our case gravity anomalies at sea level, $\mathbf{L}$ is the vector of measurements, either $T_{z z}$ or $-\left(T_{x x}+T_{y y}\right), \boldsymbol{\varepsilon}$ the vector of random noise, $\mathrm{E}\{$. $\}$ the statistical expectation, $\sigma_{0}^{2}$ a priori variance factor and $\mathbf{Q}$ the co-factor matrix of the measurements.

The system of equations (5), derived after discretisation of the integral (2) or (4), is illconditioned. This means the solution is very sensitive to noise of data and any small change in data leads to large variations in the solution after inversion. This problem can be solved by using regularisation. Tikhonov (1963) was one of the pioneers of this method and he solved the following optimisation problem to stabilise the solution:

$$
\min \left(\|\mathbf{A x}-\mathbf{L}\|_{2}+\alpha^{2}\|\mathbf{I}\|_{2}\right)
$$

where $\alpha^{2}$ is the regularisation parameter, $\mathbf{I}$ the identity matrix, and $\|\cdot\|_{2}$ stands for $\mathrm{L}_{2}$ norm.

When a system of equations is ill-conditioned the least-squares solution of the system have very large values. In fact, Tikhonov (1963) controls these values by adding $\alpha^{2}\|\mathbf{I}\|_{2}$ to the leastsquares optimisation problem, to find a balance between the estimated and residual values. The solution of Eq. (6) is:

$$
\mathbf{x}_{\text {reg }}=\mathbf{N}^{-1} \mathbf{A}^{\mathrm{T}} \mathbf{Q}^{-1} \mathbf{L} \text { where } \mathbf{N}=\mathbf{A}^{\mathrm{T}} \mathbf{Q}^{-1} \mathbf{A}+\alpha^{2} \mathbf{I} .
$$

The proper choice of $\alpha^{2}$ is the most important issue in the inversion process. Different methods have been presented for estimating the regularisation parameter. Some of these include L-curve, generalised cross validation (GCV) and normalised cumulative periodogram (NCP) (see Hansen, 2010). There is no general answer regarding which choice of parameter method is optimal. This is because each inverse problem has its own characteristics and error model, and it is somewhat unpredictable. For instance, the L-curve is suitable for larger noise level. The GCV is quite robust and accurate, as long as the noise is white while the NCP appears to work well for both noise levels (Hansen, 2010).

In essence, adding an additional $\alpha^{2}$ parameter in the stabilisation process causes the solution get a bias as a stabilisation penalty. This bias has the following formula $(\mathrm{Xu}, 1992)$ :

$$
\operatorname{bias}\left\{\mathbf{x}_{\text {reg }}\right\}=-\alpha^{2} \mathbf{N}^{-1} \mathbf{x}
$$

From Eq. (8), one can see that the bias is a function of the true values of the unknown parameters $\mathbf{x}$. Xu et al. (2006) recommended using $\mathbf{x}_{\text {reg }}$ as an approximation to $\mathbf{x}$. In this case, a $2^{\text {nd }}$-order bias comes to the solution but it is always small and negligible; see Xu et al. (2006). Therefore, this bias is estimable and reducible from the solution by: 


$$
\hat{\mathbf{x}}_{\text {reg }}=\mathbf{x}_{\text {reg }}+\alpha^{2} \mathbf{N}^{-1} \mathbf{x} .
$$

Furthermore, the variance-covariance matrix of the estimated parameters can be obtained by using the error propagation law of random errors (Eshagh and Sjöberg 2011, Eshagh 2012):

$$
\hat{\mathbf{Q}}_{\mathbf{x}_{\mathrm{reg}}}=\hat{\sigma}_{0}^{2} \mathbf{N}^{-1} \mathbf{A}^{\mathrm{T}} \mathbf{Q}^{-1} \mathbf{A} \mathbf{N}^{-1},
$$

where the a posteriori variance factor can be estimated by (Xu et al. 2006):

$$
\hat{\sigma}_{0}^{2}=\frac{\boldsymbol{\varepsilon}_{\text {req }}^{\mathrm{T}} \mathbf{Q}^{-1} \boldsymbol{\varepsilon}_{\text {reg }}-\alpha^{4} \mathbf{x}^{\mathrm{T}}\left\{\mathbf{N}^{-1}-\alpha^{2} \mathbf{N}^{-2}\right\} \mathbf{x}}{\mathrm{n}-\mathrm{r}+\alpha^{2} \operatorname{trace}\left\{\mathbf{N}^{-2}\right\}}
$$

and

$$
\boldsymbol{\varepsilon}_{\text {reg }}=\mathbf{L}-\mathbf{A} \mathbf{x}_{\text {reg }} .
$$

\section{JOINT INVERSION OF DIAGONAL COMPONENTS}

Now, two systems of equations are organised, one derived from the integral (2) and the other from (4). Solutions of both systems will be gravity anomalies at sea level over the study area. Here, we have a new Gauss-Markov model:

$$
\left[\begin{array}{l}
\mathbf{A} \\
\mathbf{A}
\end{array}\right] \mathbf{x}=\left[\begin{array}{l}
\mathbf{L}_{1} \\
\mathbf{L}_{2}
\end{array}\right]+\boldsymbol{\varepsilon}_{*} \quad, \quad \mathrm{E}\left\{\boldsymbol{\varepsilon}_{*}\right\}=0 \text { and } \mathrm{E}\left\{\boldsymbol{\varepsilon}_{*} \boldsymbol{\varepsilon}_{*}^{\mathrm{T}}\right\}=\sigma_{0}^{2}\left[\begin{array}{cc}
\mathbf{Q}_{1} & \mathbf{0} \\
\mathbf{0} & \mathbf{Q}_{2}
\end{array}\right]
$$

where $\mathbf{L}_{1}$ and $\mathbf{L}_{2}$ are, respectively, the vectors of $T_{z z}$ and $-\left(T_{x x}+T_{y y}\right)$, and $\mathbf{Q}_{1}$ and $\mathbf{Q}_{2}$ are their corresponding variance-covariance matrices. $\boldsymbol{\varepsilon}_{*}$ is the vector of random noise of the system. Solution of Eq. (13) by the Tikhonov regularisation is:

$$
\mathbf{x}_{\text {reg }}=\mathbf{M}^{-1} \mathbf{U} \text { where } \mathbf{M}=\mathbf{A}^{\mathrm{T}}\left(\mathbf{Q}_{1}^{-1}+\mathbf{Q}_{2}^{-1}\right) \mathbf{A}+\alpha^{2} \mathbf{I} \text { and } \mathbf{U}=\mathbf{A}^{\mathrm{T}} \mathbf{Q}_{1}^{-1} \mathbf{L}_{1}+\mathbf{A}^{\mathrm{T}} \mathbf{Q}_{2}^{-1} \mathbf{L}_{2} .
$$

Similarly, we can see that the regularisation bias, variance-covariance matrix of the solution are, respectively:

$$
\operatorname{bias}\left\{\mathbf{x}_{\text {reg }}\right\}=-\alpha^{2} \mathbf{M}^{-1} \mathbf{x}
$$

Therefore, the bias-corrected estimates of the unknown parameters will be:

$$
\hat{\mathbf{x}}_{\text {reg }}=\mathbf{x}_{\text {reg }}+\alpha^{2} \mathbf{M}^{-1} \mathbf{x}
$$

and

$$
\hat{\mathbf{Q}}_{\mathbf{x}_{\text {reg }}}=\hat{\sigma}_{0}^{2} \mathbf{M}^{-1} \mathbf{A}^{\mathrm{T}}\left(\mathbf{Q}_{1}^{-1}+\mathbf{Q}_{2}^{-1}\right) \mathbf{A} \mathbf{M}^{-1}
$$

where $\hat{\sigma}_{0}^{2}$ is a posteriori variance factor. The mathematical formula for computing $\hat{\sigma}_{0}^{2}$ is similar to what was presented in Eqs. (11) and (12), but it is necessary to replace $\mathbf{N}$ by $\mathbf{M}$ and $\mathbf{Q}$ by the diagonal matrix of $\mathbf{Q}_{1}+\mathbf{Q}_{2}$ and $n$ by $2 n$ in Eq. (11). It also requires to replace $\mathbf{L}$ by $\left[\begin{array}{ll}\mathbf{L}_{1} & \mathbf{L}_{2}\end{array}\right]^{\mathrm{T}}$ in Eq. (12).

\section{NUMERICAL STUDIES}

Here, we divide our numerical studies into three parts. At the first step, the study area and the data are introduced, after that, the downward continuation of the real GOCE data to gravity 
anomalies are described along with estimation of their errors. At the last step, the joint combination and inversion of diagonal components are investigated.

\subsection{STUDY AREA AND DATA}

Our study area is Ethiopia, limited between the latitudes $3{ }^{\circ} \mathrm{N}$ and $15{ }^{\circ} \mathrm{N}$ and the longitudes between $33^{\circ} \mathrm{E}$ and $48^{\circ} \mathrm{E}$. This area is further extended by $10^{\circ}$ in order to reduce the effect of the STE of the integral formula. Therefore, the data and the recovered data is now will have a boundary between latitudes $-7^{\circ} \mathrm{N}$ and $25^{\circ} \mathrm{N}$ and the longitudes between $23^{\circ} \mathrm{E}$ and $58{ }^{\circ} \mathrm{E}$. Ethiopia is characterised by complex topographic and geological structures. Its landmass is divided by the Main Ethiopian Rift into the eastern and western plateau. The Main Ethiopian Rift (MER) lies between Nubia and Somalia plates. It extends from the Afar triple junction to the Lake Turkana depression in northern Kenya (Wolfenden et al., 2004; Keir et al., 2009). There are many active volcanoes in the southern, central and north sections of the MER. Afar triangle is one of the geologically active place on our planet where three plates Nubia-Somalia and Arabia plates are converging. Many geophysical studies have been conducted to understand the geodynamics of rifting process (Furman et al., 2006). Many recent studies indicated that the MER is very active in terms of volcanism, seismicity and tectonic deformation (Ebinger et al., 2010; Bastow et al., 2008).

Besides, the country is characterised by extremely undulating topography. Figure 2 shows the topographic nature of Ethiopia. Generally, the MER is formed from low lying flat plain. Some areas in the Afar depression are below mean sea level. In these areas, height values are negative. The Somalian and Nubian plates are represented by highlands and plateaus. The western plateaus laying on the Nubian plate reaches up to 4420 meters elevation above mean sea level. It is also known that the gravity field is highly variable across the study area due to complexity in topographic mass distribution, geology, geodynamics and tectonics. 


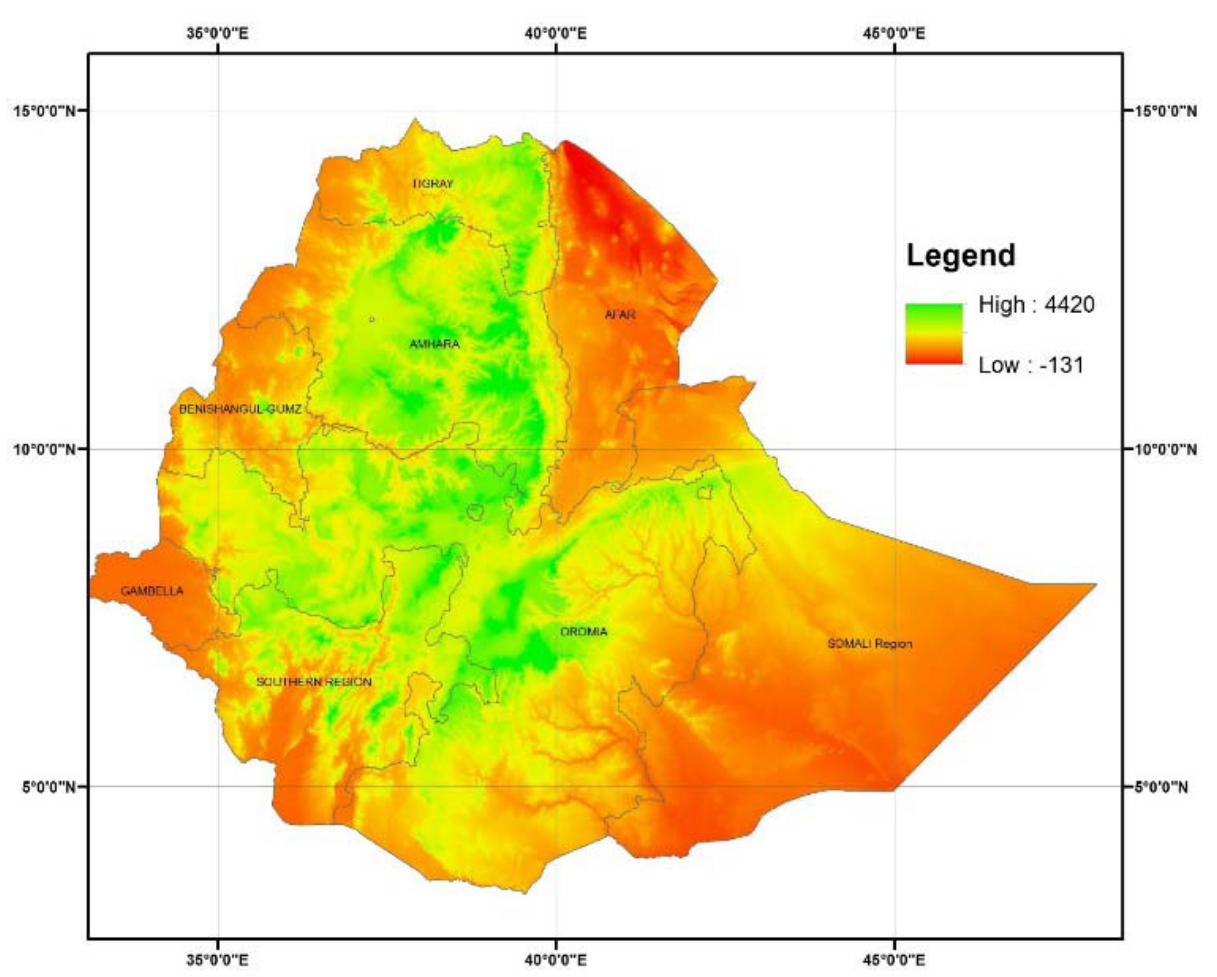

Fig 2. Study area and its topographic regime [metres]

With regard to the data needed for the study, we have used good coverage of gravitational tensor data over the entire region of Ethiopia from various orbital tracks of GOCE satellite acquired for a period of 9 months from January 2013 to September 2013 with a sampling interval of 3-seconds (Figure 3d). The GRS80 (Moritz 2000) normal gravity field model is used and the diagonal components of the tensor are regenerated by this model and subtracted from the measured components. This gives the $2^{\text {nd }}$-order derivatives of disturbing potential $(T)$ which is suitable for gravity anomaly recovery. Figures 3a,b and c show the maps of $T_{x x}, T_{y y}$ and $T_{z z}$ over the study area. Figure $3 \mathrm{a}$ is the map of $T_{x x}$ and shows that the large values of this gradient are located in the southern part of the area. Figure $3 \mathrm{~b}$ shows the structure of $T_{y y}$ and negative values over the mountains which are isolated by positive values from east and west, due to the fact that this gradient can show the inflation points of the gravity field. The map of $T_{z z}$, Figure $3 \mathrm{c}$, shows the high and positive values along the topographic features and negative values in the south-east of the area. The maps of the errors of $T_{z z}, T_{x x}$ and $T_{y y}$ are, respectively, presented In Figures $3 \mathrm{~d}$, $3 \mathrm{e}$ and $3 \mathrm{f}$ over the area. The statistics of the data and their errors are presented in Table 1. 

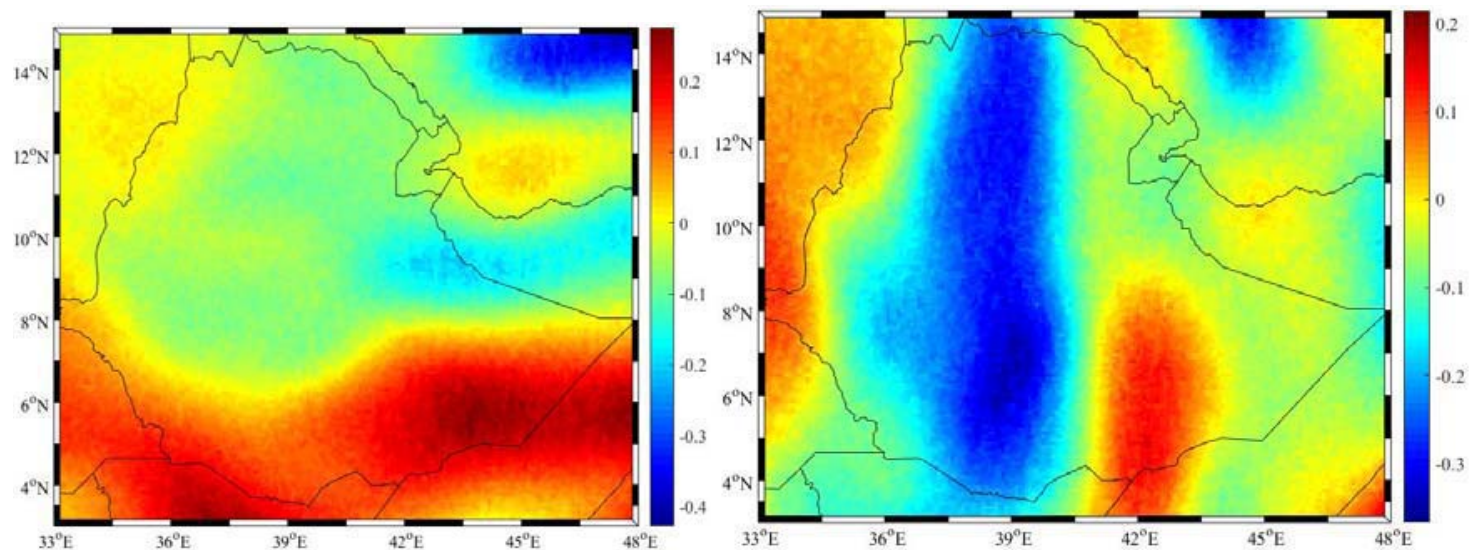

a) b)

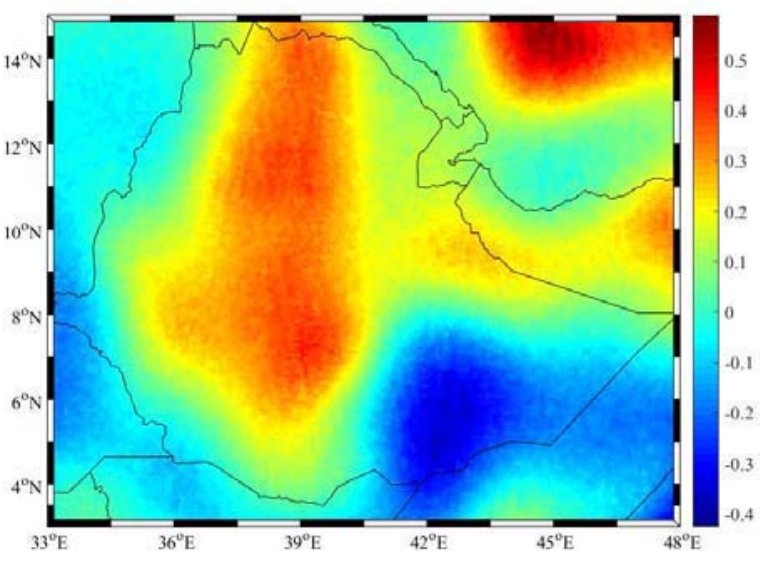

c)

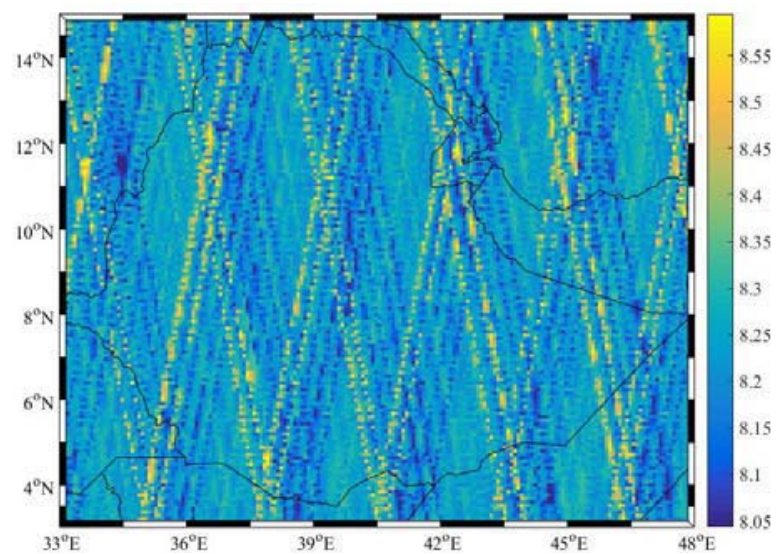

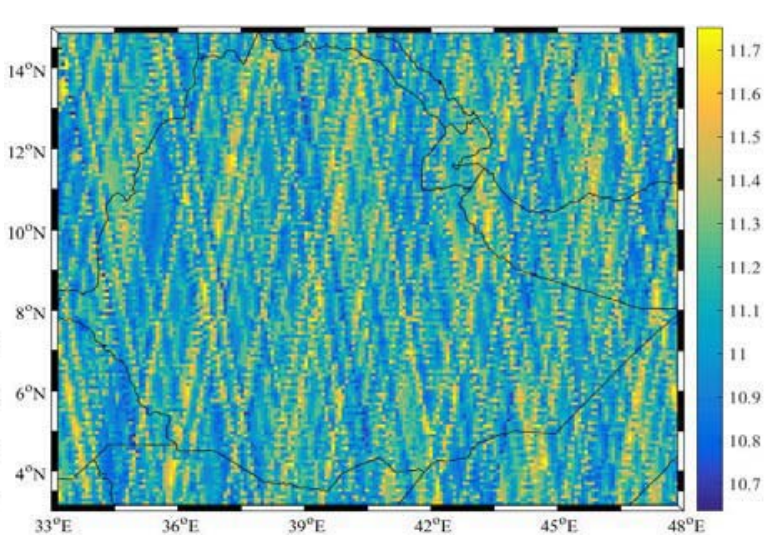

d)

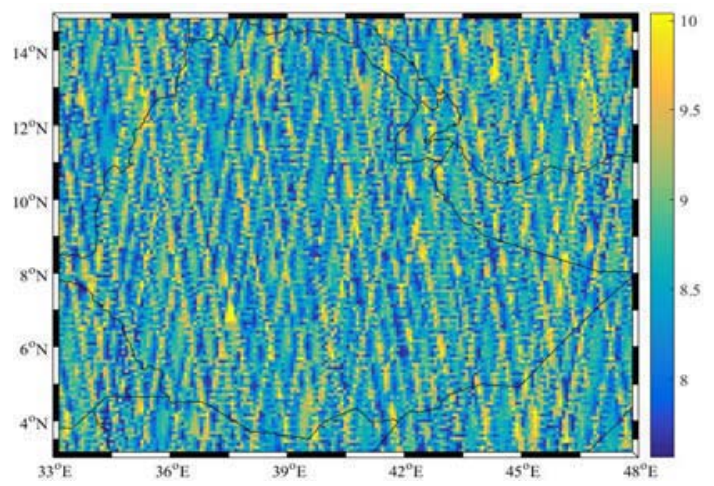

f)

Fig 3. a) $T_{x x}[\mathrm{E}]$, b) $T_{y y}[\mathrm{E}]$, c) $T_{z z}[\mathrm{E}]$, d) $\sigma_{z z}[\mathrm{mE}]$, e) $\sigma_{x x}[\mathrm{mE}]$, and f) $\sigma_{y y}[\mathrm{mE}]$

Table 1 represents the statistics of $T_{x x}, T_{y y}$, and $T_{z z}$ and their respective errors measured by GOCE. As we expected, the $T_{z z}$ has the largest magnitude comparing to $T_{x x}$ and $T_{y y}$ with a larger standard deviation. Also, the largest errors are related to the $T_{z z}$ gradients as well. 
Table 1. Statistics of the GOCE data $\left(T_{x x}, T_{y y}\right.$, and $\left.T_{z z}\right)$ and their respective errors, $\sigma_{x x}, \sigma_{y y}$ and $\sigma_{z z}$ over Ethiopia

\begin{tabular}{|c|c|c|c|c|}
\hline & Max & Mean & Min & Std \\
\hline$T_{x x}[\mathrm{E}]$ & 0.423 & 0.058 & -0.498 & 0.145 \\
\hline$T_{y y}[\mathrm{E}]$ & 0.538 & 0.015 & -0.549 & 0.168 \\
\hline$T_{z z}[\mathrm{E}]$ & 0.643 & 0.044 & -0.832 & 0.267 \\
\hline$\sigma_{x x}[\mathrm{mE}]$ & 8.595 & 8.242 & 8.043 & 0.129 \\
\hline$\sigma_{y y}[\mathrm{mE}]$ & 10.043 & 8.665 & 7.560 & 0.804 \\
\hline$\sigma_{z z}[\mathrm{mE}]$ & 11.754 & 11.153 & 10.616 & 0.314 \\
\hline
\end{tabular}

In order to check the quality of the recovered gravity anomalies, the TIM-R5 (Brockmann et al, 2014) gravity model, which was derived from the timewise analysis of GOCE data is used. This gravity model contains the spherical harmonic coefficients of the gravity field and their errors. So there is a possibility of estimating the errors of the computed gravity anomalies from this model using errors propagation law. This model has been computed from all measured data of GOCE during the mission life. The gravity anomalies generated from this model can be a good source to compare our results with it. However, we mention that since the GOCE data are used both in solution of this model and our integral inversion method, our results will be correlated with those of this model. However, we have not used all data of GOCE during its life and we considered a step interval of 3 seconds along the satellite orbit. In addition to these two differences, our method is very different from the one used for solving TIM-R5 model. The differences between our recovered gravity anomalies and those of TIM-R5 model could be due to this issue as well. Figure 4 shows the map of gravity anomalies computed by this model to degree and order 200. The anomalies ranges from -50 to $65 \mathrm{mGal}$ over the study area. The estimated errors ranges from 0.32 to $0.34 \mathrm{mGal}$ according to this model. The high values are placed along the mountains and even in the Afar region. Figure 5 shows the root mean squares error (rms) between the recovered gravity anomalies and those computed from TIM-R5 model to different degrees and orders. As the figure represents, the minimum rms is achieved for the case where TIM-R5 is limited to degree and order 200.

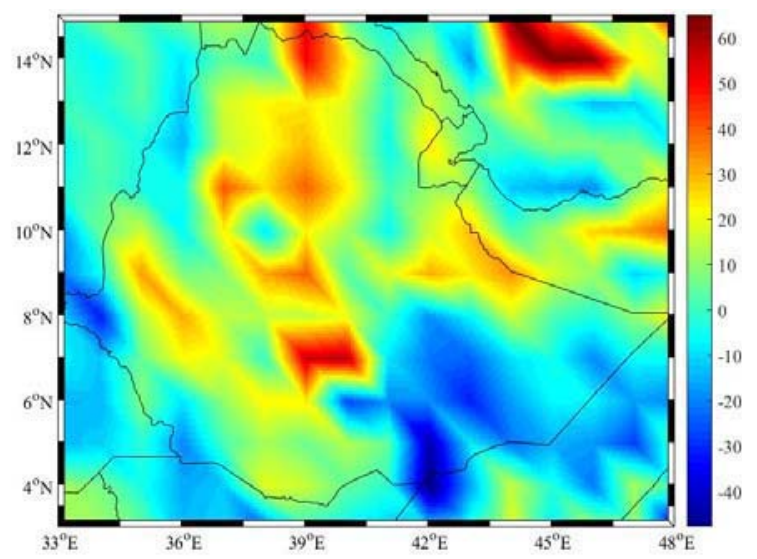

Fig 4. TIM-R5 gravity anomalies [mGal] 


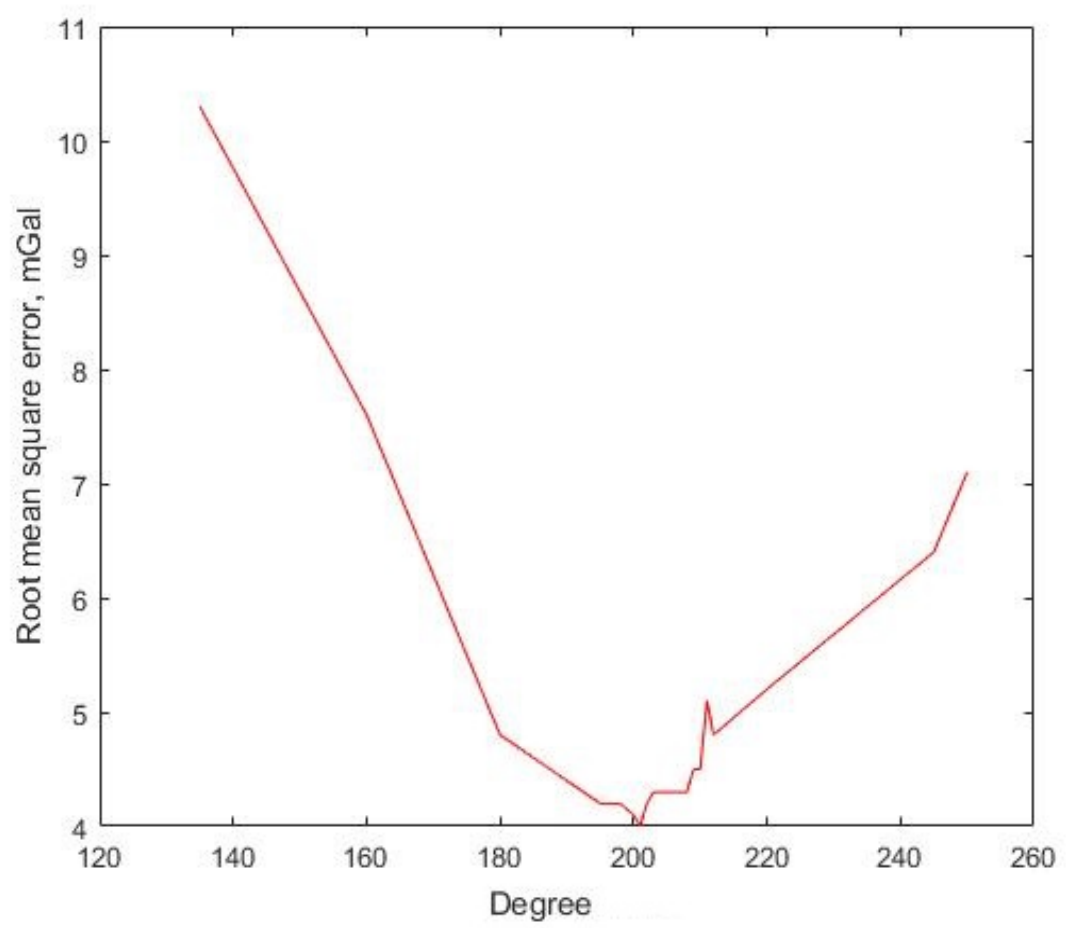

Fig 5. Rms error of differences between gravity anomalies computed from GOCE data and TIMR5 for degrees 135 to 250

\subsection{INVERSION OF THE GOCE DATA}

Now, the diagonal components of the tensor of gravitation measured by GOCE are used in three scenarios for determining the gravity anomaly at sea level. At the first step, only $T_{z z}$ is inversed, after that $T_{x x}+T_{y y}$ and finally, all of them together. Since we have used 9 months of revolution of GOCE with a sampling interval of 3-seconds, we will have about 113000 values for each set of $T_{z z}$, and $T_{x x}+T_{y y}$. In the case of combing these measurements the number of observations will be twice larger, whilst the number of unknowns remains the same for all cases according to the resolution of recovery which is $1^{\circ} \times 1^{\circ}$.

As explained before, our system of equations is ill-conditioned and we have to use a regularisation method for solving them. Here, we use the well-known Tikhonov regularisation (Tikhonov, 1963) and use Generalised Cross validation (GCV) for determining the regularisation parameter. We have used different methods for estimating this parameters, but we obtained the best results when we used the GCV method. The Regularisation Toolbox of Matlab (Hansen, 2007) has been used for solving the system of equations.

Each scenario is done in 4 cases before and after bias-correction process with and without considering the errors of GOCE data in inversion. The statistics of our computations are presented in Table 2. The gravity anomalies recovered from, $T_{z z},-\left(T_{x x}+T_{y y}\right)$ and their combination, are shown by $\Delta g^{T_{z z}}, \Delta g^{-\left(T_{x x}+T_{y y}\right)}$ and $\Delta g^{T_{z z},-\left(T_{x x}+T_{y y}\right)}$, respectively. $\mathbf{Q}=\mathbf{I}$ means that an identity matrix (I) is considered instead of the co-factor matrix, or in other words, the precision of data is ignored, and $\mathbf{Q} \neq \mathbf{I}$, the case that the errors of data are considered. 
During our investigation we found out that in the case of considering the errors of the data, and defined a weight matrix in the inversion process, the system of equations became stable and the regularisation parameter came out considerably close to zero. This caused that the statistics before and after bias-correction remains the same. As Table 2 shows, those cases in which errors of the data are ignored and an identity matrix is considered as the weight matrix in solving the system of equations, the results are closer to the gravity anomalies of the TIM-R5 model. This means that the weight of data, or the presented errors, do not express the quality of the GOCE data correctly. Some low-quality data get larger weights and high-quality ones lower in the inversion process. This causes that the solution deviates from what we obtain without considering the weights. Even bias-correction does not improve the estimates, gravity anomalies obtained from the inversion of $T_{z z}$ and $T_{x x}+T_{y y}$ have root mean square errors in the order of 4.2 and 4.1 mGal, respectively.

In order to see if the differences between the recovered gravity anomalies are significant, we use Eqs. (10) and (16) to estimate the errors of the anomalies. The errors of recovered anomalies

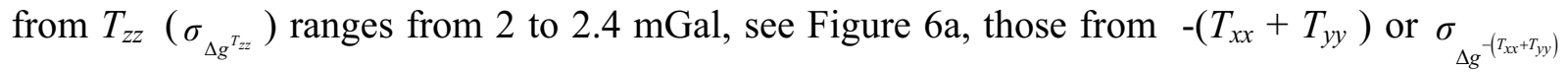
ranges from 2 to $2.7 \mathrm{mGal}$; see Figure $6 \mathrm{~b}$. This is expected as in the second case, two sets of observation are used and each one has its own error. Therefore, the error of $-\left(T_{x x}+T_{y y}\right)$ is expected to be larger according to the error propagation law. In addition, the same system of equations is used for inverting $T_{z z}$ and $-\left(T_{x x}+T_{y y}\right)$, therefore, the difference between the estimated errors are solely due to the errors of the data. In the case of combining $T_{z z}$ and $-\left(T_{x x}+\right.$

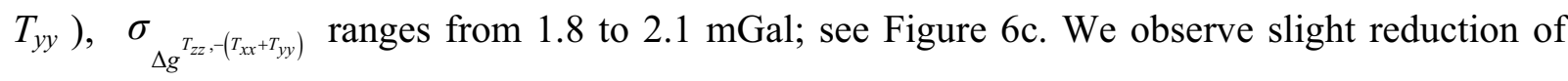
errors due to larger number of observations in our system. We can observe that combining these two sets of data leads to smaller error.

Table 2. Statistics of estimated gravity anomalies over Ethiopia determined by inverting $T_{z z}$, - $\left(T_{x x}\right.$ $\left.+T_{y y}\right)$ and combination of them, before and after bias-correction. [mGal]

\begin{tabular}{|c|c|c|c|c|c|c|c|c|c|c|}
\hline & \multicolumn{5}{|c|}{ Before bias-correction } & \multicolumn{5}{c|}{ After bias-correction } \\
\hline & Max & Mean & Min & Std & rms & Max & Mean & Min & Std & rms \\
\hline$\Delta g^{T_{z z}}, \mathbf{Q}=\mathbf{I}$ & 11.6 & -0.4 & -12.6 & 4.2 & 4.2 & 12.8 & -0.4 & -15.6 & 4.8 & 4.8 \\
\hline$\Delta g^{T_{z z}} \mathbf{Q} \neq \mathbf{I}$ & 13.7 & -0.4 & -18.0 & 5.5 & 5.6 & \multicolumn{4}{|c|}{ The same as before bias-correction } \\
\hline$\Delta g^{-\left(T_{x x}+T_{y y}\right)}, \mathbf{Q}=\mathbf{I}$ & 11.6 & -0.4 & -10.4 & 4.1 & 4.1 & 14.2 & -0.3 & -12.8 & 4.7 & 4.7 \\
\hline$\Delta g^{-\left(T_{x x}+T_{y y}\right)}, \mathbf{Q} \neq \mathbf{I}$ & 15.8 & -0.4 & -14.6 & 5.1 & 5.7 & \multicolumn{4}{|c|}{ The same as before bias-correction } \\
\hline$\Delta g^{T_{z z},-\left(T_{x x}+T_{y y}\right)}, \mathbf{Q}=\mathbf{I}$ & 12.7 & -0.4 & -10.8 & 4.1 & 4.1 & 14.2 & -0.4 & -12.4 & 4.5 & 4.5 \\
\hline$\Delta g^{T_{z z},-\left(T_{x x}+T_{y y}\right)}, \mathbf{Q} \neq \mathbf{I}$ & 14.7 & -0.4 & -12.9 & 4.7 & 4.7 & \multicolumn{6}{|c|}{ The same as before bias-correction } \\
\hline
\end{tabular}

Generally, by looking at the statistics we cannot say that if the differences between the gravity anomalies recovered from $T_{z z}$ and $-\left(T_{x x}+T_{y y}\right)$ are significant or not. To have a better idea, we plot the map of the absolute values of the differences between the gravity anomalies in Figure 7a. In this map, we do not observe large errors around the area as 1) we have reduced the STE from the estimated gravity anomalies, 2) this error is the same in both cases of inverting $T_{z z}$ and $-\left(T_{x x}+T_{y y}\right)$. Therefore, by subtracting them from each other the STE is eliminated. We observe that the 
differences reach to $9 \mathrm{mGal}$ in the northern part of the area, even if the statistics do not show it. In order to test if these differences are significant, we estimate the errors of the recovered anomalies. The square root of sum of their variances, will give the propagated error for the differences of the gravity anomalies. Figure $7 b$ shows the map of the estimated error of the differences, and we see that they reach to a maximum value of $3.7 \mathrm{mGal}$. However, the pattern of these errors is not similar to that of the differences. Therefore, we should check at which points these errors are smaller or larger than the absolute value of the differences, using:
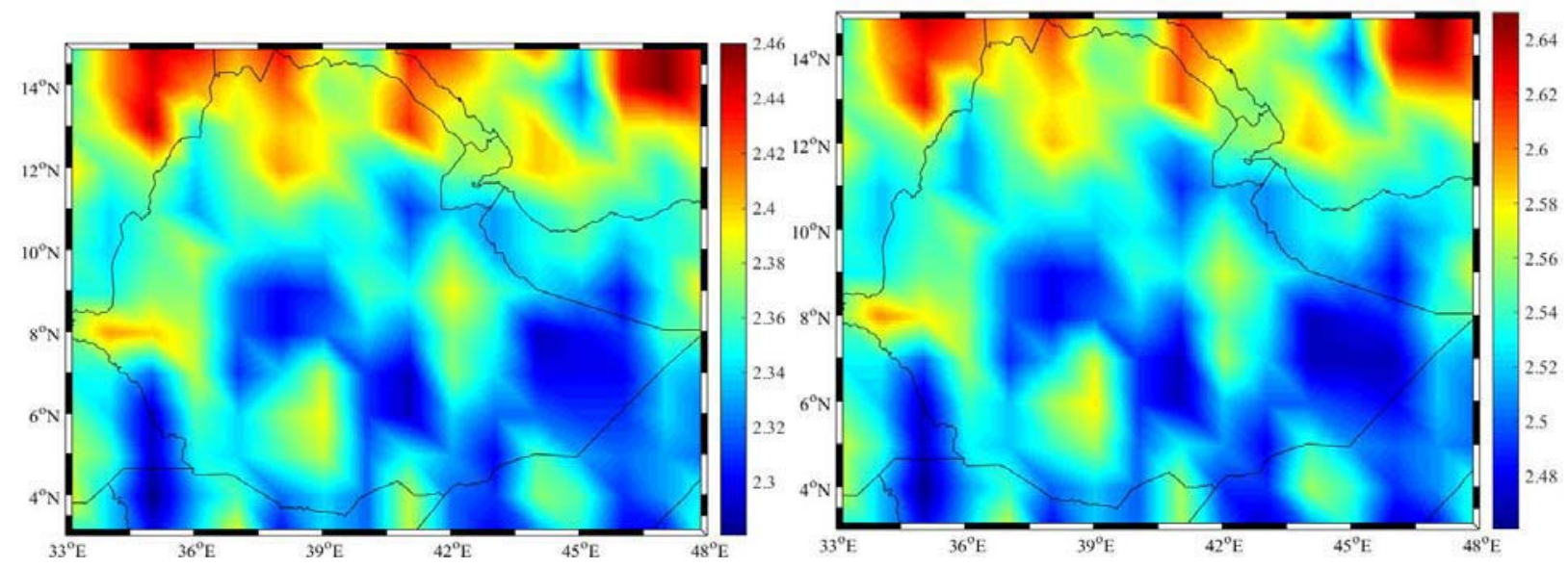

a)

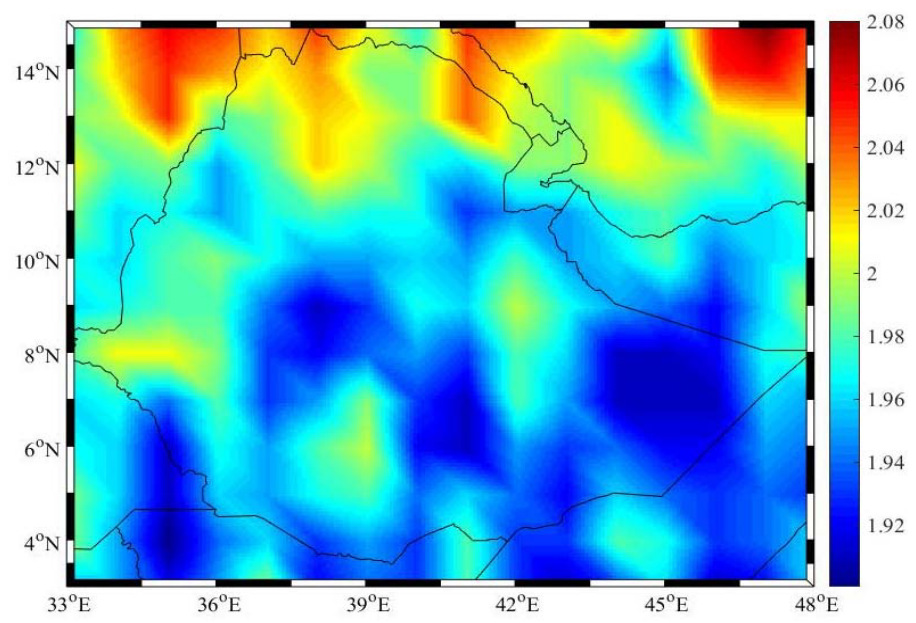

b)

c)

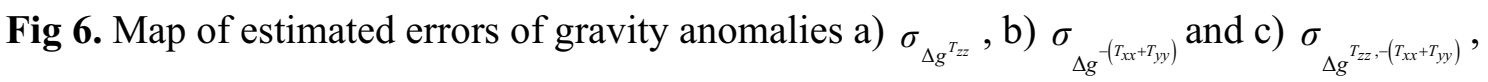

$$
\left|\Delta g^{T_{z z}}-\Delta g^{-\left(T_{x x}+T_{y y}\right)}\right| \geq \sqrt{\sigma_{\Delta g^{T_{z z}}}^{2}+\sigma_{\Delta g^{-\left(T_{x x}+T_{y y}\right)}}^{2}}
$$

For those points having larger differences than their corresponding errors, the improvements are significant. In Figure 7c, we show the ratio of the absolute differences and the estimated errors of the differences. Those regions showing larger values than 1 , shows that significant differences, which are not seen well by the statistics in Table 2. 


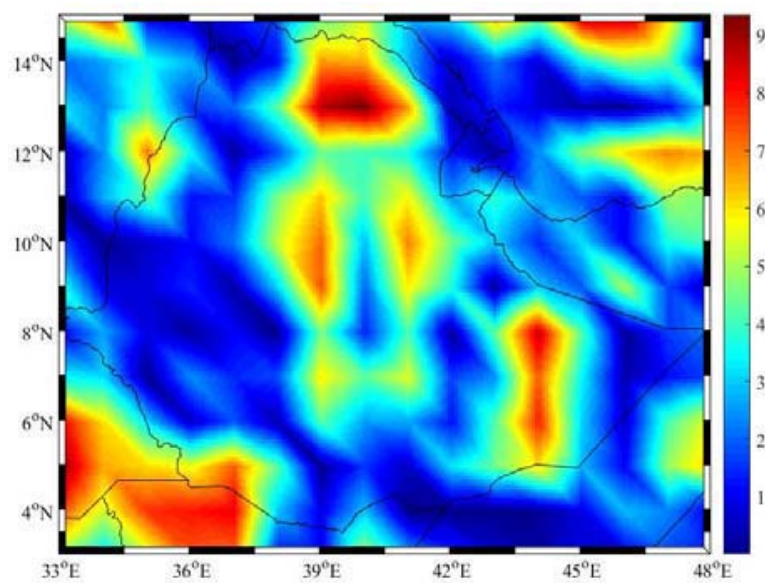

a)

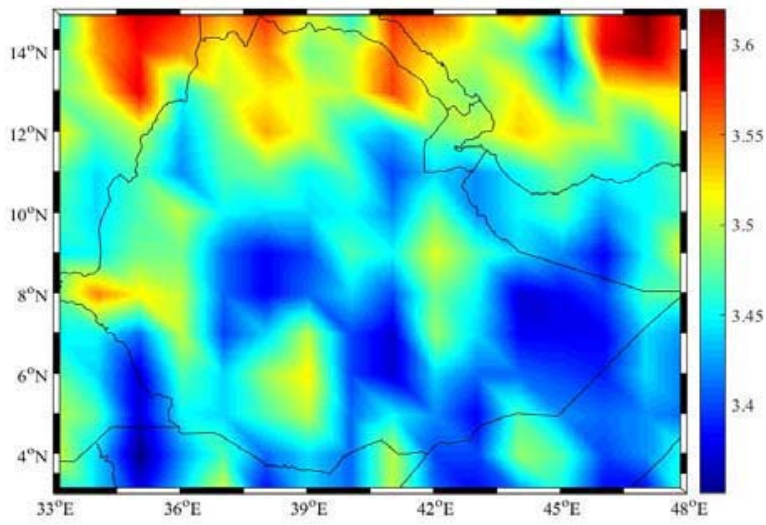

b)

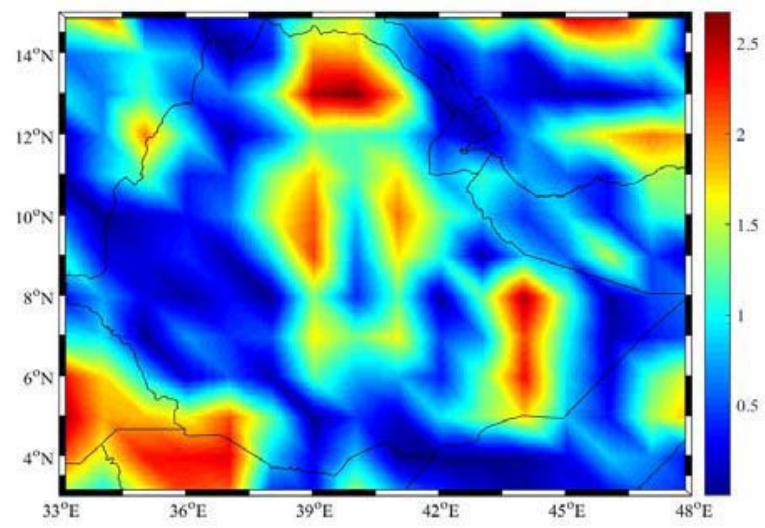

Fig 7. a) Absolute value of differences between the gravity anomalies recovered from $T_{z z}$ and $\left.\left(T_{x x}+T_{y y}\right), \mathrm{b}\right)$ square root of sum of the variances of the anomalies and c) ratio of the absolute values and the errors. [mGal]

Figure $8 \mathrm{a}$ is the map of the absolute values of the differences between the gravity anomalies recovered from joint inversion of $T_{z z}$ and $-\left(T_{x x}+T_{y y}\right)$ and those computed from the TIM-R 5 model. We admit that since both computed anomalies uses the GOCE data they are correlated. However, we emphasise our study has the following differences comparing to the solution of TIM-R5:

- integral inversion of in-orbit GOCE data with a local coverage has been performed.

- only the diagonal components are used, not all components of gravitational tensor.

- a limited period of revolution is considered from January to September 2013, with a sampling rate of $3 \mathrm{sec}$.

Considering the above issues, we observe that the differences reach to $16 \mathrm{mGal}$ in some areas. The square root of the variance of the differences are about $2 \mathrm{mGal}$, see Figure $8 \mathrm{~b}$.

$$
\left|\Delta g^{\mathrm{TIM} 5}-\Delta g^{T_{z z},-\left(T_{x x}+T_{y y}\right)}\right| \geq \sqrt{\sigma_{\Delta g^{\mathrm{TIMS}}}^{2}+\sigma_{\Delta g^{T_{z z},-\left(T_{x x}+T_{y y}\right)}}^{2}}
$$


Again in order to see if the differences are significant we are in the significant level of $32 \%$, Eq. (19) is used. This equation means that those differences, which have larger size than the errors of the differences, are significantly large. Figure 8c shows the ratio of the absolute differences and their errors. Those places shown by larger values than 1 means that the differences are significant.
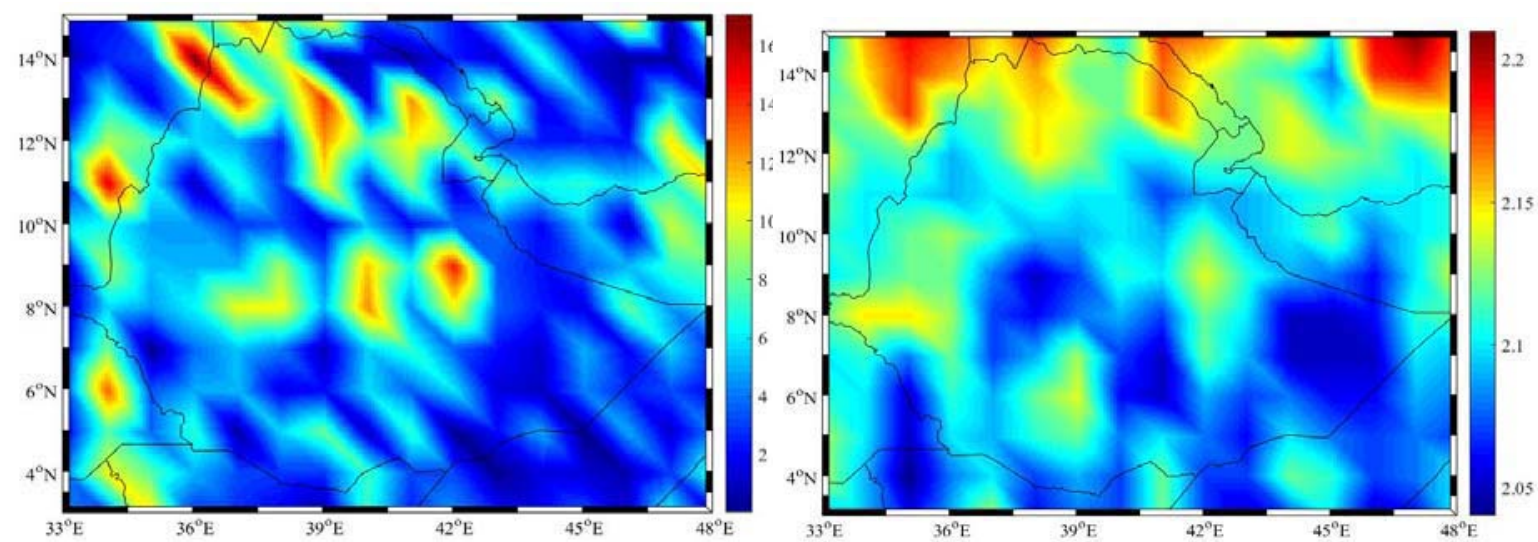

a)

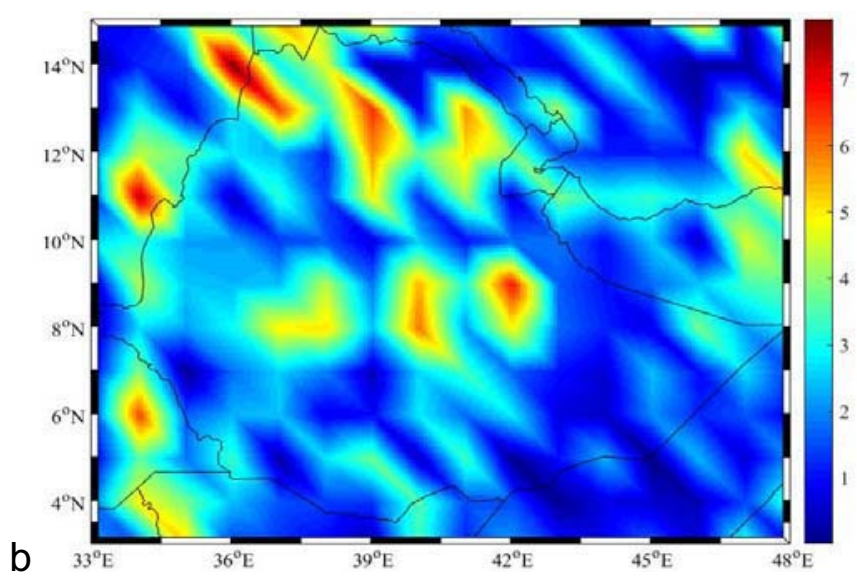

c)

Fig 8. a) Absolute values of differences between the gravity anomalies recovered from combined $T_{z z}$ and $-\left(T_{x x}+T_{y y}\right)$ and TIM-R5 model, b) square root of sum of the variances of the anomalies and c) ratio of the absolute values and the errors. [mGal]

Eshagh and Sjöberg (2011) used simulated satellite gradiometry data at mean orbit of $250 \mathrm{~km}$ contaminated by $1 \mathrm{mE}$ and $10 \mathrm{mE}$ to recover gravity anomaly at mean sea level using integral inversion. They showed that recovering gravity anomalies is possible with accuracies of 3.3 and $6.13 \mathrm{mGal}$, respectively, for $1 \mathrm{mE}$ and $10 \mathrm{mE}$ noise levels in Fennoscandia. However, they have not considered the STE of the integral formula and solely focused on the quality of inversion and solving the system of equations derived after discretisation of the integral equations. Eshagh (2011a) discussed the relevance of the components of the gravitational tensor for local gravity field recovery and concluded that only the diagonal components of this tensor are suited for this purpose. Eshagh (2012) also tried to recover the gravity anomalies from $T_{z z}$ even in the presence of STE and mentioned that they can be recovered with an accuracy of $6 \mathrm{mGal}$. All of these studies have been based on the simulated data. Yildiz (2012) applied least-square collocation 
(LSC) for the same purpose but using real data. He removed the long wavelength effect using EGM2008 and the short wavelength part by residual terrain models and recovered anomalies. Removing the long and short wavelength structures of the gravity field correlates the GOCE data with this a priori information. At the end, Yildiz (2012) estimated an error of $11 \mathrm{mGal}$ for the anomalies. Eshagh and Ghorbannia (2014) used the real data of GOCE for the same purpose over Fennoscandia and could recover them with an accuracy of $6.1 \mathrm{mGal}$, which was not very different with those obtained by simulation studies. Later Pitoňák (2016a) uses three approach for recovering regional gravity disturbance at mean sea level. The first approach applies integral inversion of satellite gradiometry data sampled at 0.5 degree from real GOCE data at mean orbital height of $250 \mathrm{~km}$, whilst we have used the in-orbit GOCE data as interpolating them at this mean height correlates the data. They considered the far zone effects by a global gravity model, meaning that they used some priori information. In their second approach, the gravitational effects of the topographic masses are removed prior to continue the data downward and the third one was based on the remove-compute-restore scheme, similar to what Yildiz (2012) did. This approach performed better and they could receive the anomalies with an accuracy of $2.9 \mathrm{mGal}$. Similarly, Pitoňák (2016b) recovered disturbing potential at mean sea level instead of gravity anomalies. Sharifi et al (2017) used simulated second and third-order disturbing potentials and showed that the anomalies can be estimated with an accuracy of 7.8 mGal from integral inversion of $T_{z z}$ over Fennoscandia. The presented accuracies for the recovered anomalies depends on duration of the GOCE data, sampling rate, resolution of recovery and STE. Here, we used the GOCE data with a sampling interval of $3 \mathrm{sec}$ under a period of 9 months. No remove-compute-restore is done in our method, and the GOCE data are not gridded either. The STE was reduced by extending our study area further by $10^{\circ}$. However, resolution of recovery was $1^{\circ} \mathrm{x} 1^{\circ}$ and the recovered anomalies are compared with those obtained from TIM-R5 gravity model truncated at degree and order 200 . We could recover the anomalies with an rms of $4 \mathrm{mGal}$ comparing to TIM-R5 anomalies. Also, we have performed some error analysis over the recovered anomalies.

\section{CONCLUSION}

We recovered the gravity anomaly in Ethiopia from real in-orbit diagonal components of the gravitational tensor measured by GOCE during a 9-month period of January to September 2013, with a sampling interval of $3 \mathrm{sec}$. The Tikhonov regularisation was used for solving and stabilising the system of equations, derived following the discretisation of the integral equations, and GCV method was used for estimating the regularisation parameter. Comparison of our recovered gravity anomalies to those derived from the TIM-R5 gravity model shows that the rms values of the differences are not significantly different. However, the joint inversion of $T_{z z}$ and $\left(T_{x x}+T_{y y}\right)$ produces closer anomalies to those of TIM-R5 with an rms of about $4.1 \mathrm{mGal}$. In addition our numerical results show that the local recovery of the gravity anomalies are more successful when the data are equally weighted. This means that considering the errors of the GOCE data corrupts the solution, rather than improving it. This can be due to the incorrect errors of the data, those data having higher qualities gets lower weights and those with lower gets higher. This causes that the solution not to be close to that of TIM-R5, which we considered as the reference model. Furthermore, the system of equations was stable when the errors of the data are considered during the inversion as the small values of errors correspond to large values of the weights, which can improve the condition of the coefficients matrix of the normal system of equations. However, the solution is not better than the case, where the errors are ignored. The 
comparison between the recovered anomalies from $T_{z z}$ and $-\left(T_{x x}+T_{y y}\right)$ shows that the rms values of the differences are not significantly different over the study area. The absolute values of the differences reach to about $9 \mathrm{mGal}$ over the mountainous regions, showing some significant difference between the solutions comparing to the errors of the differences. Joint inversion of $T_{z z}$ and $-\left(T_{x x}+T_{y y}\right)$ delivers closer anomalies to those of TIM-R5, with an rms of about $4 \mathrm{mGal}$, and the estimated errors from this joint inversion is about $2 \mathrm{mGal}$. However, the differences reach to $16 \mathrm{mGal}$ over some places and they are significant comparing to the errors of the differences. The use of limited data over the area with a limited period of revolution, local integral inversion and using only diagonal components are the reason explaining the significant differences.

\section{Acknowledgements}

We would like to thank Entoto Observatory and Research Center, Ethiopian Space Science and Technology Institute for supporting the second author to pursue his doctoral study. Likewise, we thank the European Space Agency for making the GOCE data freely available.

\section{REFERENCES}

Arabelos, D., Tscherning, C.C. (1990). Simulation of regional gravity field recovery from satellite gravity gradiometer data using collocation and FFT, Bull. Geod. 64, 363-382.

Arabelos, D., Tscherning, C.C. (1993). Regional recovery of the gravity field from SGG and SST/GPS data using collocation, in: Study of the gravity field determination using gradiometry and GPS, Phase 1, Final report ESA Contract 9877/92/F/FL.

Arabelos, D., Tscherning, C.C. (1995). Regional recovery of the gravity field from satellite gradiometer and gravity vector data using collocation, J. Geophys. Res. 100 (B11), 2200922015.

Bastow, I.D., Nyblade, A.A., Stuart, G.W., Rooney, T.O. (2008). Upper mantle seismic structure beneath the Ethiopian hot spot: Rifting at the edge of the African low-velocity anomaly; $A n$ electronic journal of the Earth Sciences, Geochemistry, geophysics, Geosystems, 9(12), doi:10.1029/2008GC002107.

Brockmann, J. M., Zehentner, N., Hock, E., Pail, R., Loth, I., Mayer-Gurr, T., Schuh, W. D. (2014).

EGM_TIM_RL05: An independent geoid with centimeter accuracy purely based on the GOCE mission; Geophysical Research Letters, Vol 41, No. 22, p. 8089-8099, doi: $10.1002 / 2014 \mathrm{~g} 1061904$.

Ebinger, C., Ayele, A., Keir, D., Rowland, J., Yirgu, G., Wright, T., Belachew, M., Hamling, I. (2010). Length and Timescales of Rift Faulting and Magma Intrusion: The Afar Rifting Cycle from 2005 to Present; Annu. Rev. Earth Planet. Sci. 38:437-64.

Eicker, A. (2008). Gravity Field Refinement by Radial Basis Functions from In-siut Satellite Data, Institut für Geodäsie und Geoinformation, Universität Bonn, Schriftenreihe no. 10.

Eicker A., Schall J., Kusche J. (2013). Regional gravity modelling from spaceborne data: case studies with GOCE, Geophys. J. Int., 196:1431-1440, doi: https://doi.org/10.1093/gji/ggt485.

ESA. (1999). Gravity Field and Steady-State Ocean Circulation Mission, ESA SP- 1233(1), Report for mission selection of the four candidate earth explorer missions. ESA Publications Division, July 1999, p. 217. 
Eshagh, M. (2011a). On integral approach to regional gravity field modelling from satellite gradiometric data, Acta Geophys. 59, 29-54.

Eshagh, M. (2011b). Inversion of satellite gradiometry data using statistically modified integral formulas for local gravity field recovery, Adv. Space Res. 47(1), 74-85.

Eshagh, M. (2011c). The effect of spatial truncation error on integral inversion of satellite gravity gradiometry data, Adv. Space Res., 47, 1238-1247.

Eshagh, M. (2012). Spectral Combination of Spherical Gradiometric Boundary-Value Problems: A Theoretical Study, Pure Appl. Geophys., 169, 2201-2215.

Eshagh, M. and Ghorbannia M. (2013). The use of Gaussian equations of motions of a satellite for local gravity anomaly recovery, Adv. Space Res. 52, 1, 30-38.

Eshagh M, Ghorbannia M. (2014). The effect of the spatial truncation error on the variance of gravity anomalies derived from inversion of satellite orbital and gradiometric data. Advances in Space Research 54: 261-271.

Eshagh, M., Sjöberg L.E. (2011). Determination of gravity anomaly at sea level from inversion of satellite gravity gradiometric data, J. Geodyn., 51, 366-377.

Eshagh, M., Lemoine J.M., Gegout P., Biancale R. (2013). On regularized time varying gravity field models based on GRACE data and their comparison with hydrological models, Acta Geophys. 61, 1, 1-17.

Furman, T., J. Bryce, B. Hanan, G. Yirgu, and D. Ayalew (2006). Heads and tails: 30 years of the Afar plume, in The Structure and Evolution of the East African Rift System in the Afar Volcanic Province; edited by G. Yirgu, C. J. Ebinger, and P. K. H. Maguire, Geol. Soc. London Spec. Publ., 259, 95 - 119.

Hansen, P.C. (2007). Regularization Tools version 4.0 for Matlab 7.3, Numerical Algorithms, 46: p. $189-194$.

Hansen P. C. (2010). Discrete inverse problems: Insight and algorithms. SIAM fundamentals and algorithms series, Philadelphia, USA.

Janák, J., Fukuda, Y., Xu, P. (2009). Application of GOCE data for regional gravity field modeling, EPS 61, 835-843.

Janák, J., Pitoňák, M. \& Minarechová, Z. (2014). Regional quasigeoid from GOCE and terrestrial measurements, Stud. Geophys. Geod., 58, 626-649.

Keir, D., I. Hamling, A. Ayele, E. Calais, C. Ebinger, and Wright T. (2014) Evidence for focused magmatic accretion at segment centers from lateral dike injections captured beneath the Red Sea Rift in Afar; Geology, 37, 59-62, doi:10.1130/G25147A.1.

Kotsakis, C. (2007). A covariance-adaptive approach for regularized inversion in linear models, Geophys. J. Int. 171, 509-522.

Krarup, T. (1969). A contribution to the mathematical foundation of physical geodesy. Danish Geodetic Institute, Copenhagen, vol 44.

Moritz H. (2000). Geodetic Reference System 1980. Journal of Geodesy 74: 128-162. 
Naeimi M., Bouman J. (2017). Contribution of the GOCE gradiometer components to regional gravity solutions, Geophys. J. Int., 209:559-569, doi: https://doi.org/10.1093/gji/ggx040.

Pitoňák, M., Šprlák, M., Novák, P., Tenzer, R., (2016a). Regional gravity field modelling from GOCE observables, Advances in Space Research, doi: http://dx.doi.org/10.1016/j.asr.2016.09.024.

Pitoňák, M., Šprlák, M., Hamáčková, E. \& Novák, P. (2016b). Regional recovery of the disturbing gravitational potential by inverting satellite gravitational gradients, Geophys. $J$. Int., 205, 89-98.

Pitoňák, M., Šprlák, M., Tenzer, R. (2017). Possibilities of inversion of satellite third-order gravitational tensor on to gravity anomaly: a case study for central Europe, Geophys. J. Int., 209, 799-812.

Reed, G.B. (1973). Application of kinematical geodesy for determining the shorts wavelength component of the gravity field by satellite gradiometry, Ohio state University, Dept. of Geod. Science, Rep. No. 201, Columbus, Ohio.

Sebera J, Pitoňák M, Hamáčková E, Novák P. (2015). Comparative study of the spherical downward continuation. Surveys in Geophysics 36: 253-267.

Seeber, G. (2003). Satellite Geodesy: foundations, methods and applications, Walter de Gruyter $\mathrm{GmbH} \& \mathrm{Co} . \mathrm{KG}$, Berlin.

Sharifi, M. A., Romeshkani, M., Tenzer, R. (2017). On inversion of the second- and third-order gravitational tensors by Stokes' integral formula for a regional gravity recovery, Stud. Geophys. Geod. 61, 453-468.

Sjöberg L.E. and Eshagh M. (2012). A theory on geoid modeling by spectral combination of data from satellite gravity gradiometry, terrestrial gravity and an Earth gravitational model, Acta Geod. Geophys. Hung., 47, 1, 13-28.

Šprlák, M. and Novák, P. (2014) Integral transformations of gradiometric data onto GRACE type of observable, $J$ Geod. 88, 4, 377-390.

Šprlák, M., Sebera, J., Val'ko, M., Novák, P. (2014) Spherical integral formulas for upward/downward continuation of gravitational gradients onto gravitational gradients, $J$ Geod., 88, 2, 179-197.

Tikhonov, A. N. (1963). Solution of incorrectly formulated problems and regularization method, Soviet Math. Dokl., 4: 1035-1038, English translation of Dokl. Akad. Nauk. SSSR, 151, 501504.

Tóth, G, Földváry, L., Tziavos, I. N., Ádám J. (2004). Upward / downward continuation of gravity gradients for precise geoid determination, In: Proceedings of The 2nd International GOCE User Workshop: GOCE, The Geoid and Oceanography. Frascati, Italy, 2004.03.082004.03.10. 2004. pp. 249-254. Vol. SP-569.

Tscherning, C.C. (1988). A study of satellite altitude influence on the sensitivity of gravity gradiometer measurements. DGK, Reihe B, Heft Nr. 287 (Festschrift R. Sigl), pp.218-223, Muenchen. 
Tscherning, C.C. (1989) A local study of the influence of sampling rate, number of observed components and instrument noise on $1 \mathrm{deg}$. mean geoid and gravity anomalies determined from satellite gravity gradiometer measurements. Ric. Geod. Topo. Foto. 5, 139-146.

Tscherning, C.C., Forsberg, R., Vermeer, M. (1990). Methods for regional gravity field modelling from SST and SGG data. Reports of the Finnish Geodetic Institute, No. 90:2, Helsinki.

Wolfenden, E., C. Ebinger, G. Yirgu, A. Deino, and D. Ayalew (2004). Evolution of the northern Main Ethiopian Rift: Birth of a triple junction, Earth Planet. Sci. Lett., 224, 213-228.

$\mathrm{Xu}, \mathrm{P}$. (1992). Determination of surface gravity anomalies using gradiometric observables, Geophys. J. Int. 110, 321-332.

Xu, P. (1998). Truncated SVD methods for discrete linear ill-posed problems, Geophys. J. Int. $135,505-514$.

$\mathrm{Xu}, \mathrm{P}$. (2009). Iterative generalized cross-validation for fusing heteroscedastic data of inverse illposed problems, Geophys. J. Int. 179, 182-200.

Xu, P., Shen, Y., Fukuda, Y. and Liu, Y. (2006). Variance component estimation in linear inverse ill-posed models. J Geod. 80, 69-81.

Yildiz, H. (2012) A study of regional gravity field recovery from GOCE vertical gravity gradient data in the Auvergne test area using collocation, Stud. Geophys. Geod. 56, 171-184.

Received: 2017-12-22,

Reviewed: 2018-02-02 and 2018-02-23, by M. Pitoňák,

Accepted: 2018-02-23. 